Frank Gonzatti, Vinícius Nizolli*, Fredi Zancan Ferrigolo, Felix Alberto Farret and Marcos Augusto Silva de Mello

\title{
Experimental Hydrogen Plant with Metal Hydrides to Store and Generate Electrical Power
}

DOI 10.1515/ijeeps-2015-0081

\begin{abstract}
Generation of electrical energy with renewable sources is interruptible due to the primary energy characteristics (sun, wind, hydro, etc.). In these cases, it is necessary to use energy storage so increasing penetrability of these sources connected to the distribution system. This paper discusses in details some equipment and accessories of an integrated power plant using fuel cell stack, electrolyzer and metal hydrides. During the plant operation were collected the power consumption data and established the efficiency of each plant component. These data demonstrated an overall efficiency of about $11 \%$ due to the low efficiencies of the commercial electrolyzers and power inverters used in the experiments.
\end{abstract}

Keywords: energy storage, experimental plant, hydrogen, metal hydrides

\section{Introduction}

In recent years, developed and developing countries have sought for new alternatives of energy generation to support their economical and industrial needs. It is evident that every country wants to assure its energy matrix and diversified supplies. The energy dependence on other countries can be an expensive, unstable and sometimes, an unsafe alternative.

A feature that makes the alternative sources of energy more attractive is the possibility of their interconnection to the power grid (distributed generation), in contrast to the conventional schemes whose power supplies depend only on large centralized generating plants. Distributed generation systems, such as photovoltaic and wind energy, in addition to increase energy availability, can contribute to reduce emission of pollutants [1].

*Corresponding author: Vinícius Nizolli, Federal University of Santa Maria - CEESP, Santa Maria, RS, Brazil

Frank Gonzatti, Fredi Zancan Ferrigolo, Felix Alberto Farret, Federal University of Santa Maria - CEESP, Santa Maria, RS, Brazil

Marcos Augusto Silva de Mello, Company of Generation and Transmission of Electricity in the state of Rio Grande do Sul - CEEE GT, Porto Alegre, RS, Brazil
Variations and discontinuities in power supply are a characteristic of the alternative primary sources. Sometimes their underutilization or idleness during some periods of grid low demand can cause voltage fluctuations and distortions, compromising quality, stability and reliability of the power system $[2,3]$.

To minimize instabilities of renewable sources, energy storage is used to provide a surplus production in the critical demand periods and to act as generation regulators and boosters [4]. Moreover, the energy stored in advance can serve as a complement in the high demand periods, as well to supply energy during periods when the primary source is not available at all. Therefore, energy storage plays a key role when used in conjunction with geographically isolated electricity sources or in places distant from the power grid.

Energy storage systems can be classified with respect to their physical characteristics, into six categories: mechanical, chemical, electrochemical, thermal, electric field and magnetic field [5]. When compared to the conventional methods of energy storage, the hydrogen (chemical energy) stands out for their high energy density, very low self-discharge and availability everywhere in the world. Hydrogen $\left(\mathrm{H}_{2}\right)$ produced using zero-emission renewable energy sources can be considered a versatile energy carrier for the future to complement electricity demands and as a potential substitute of fossil fuels [6]. Furthermore, the hydrogen storage technology has characteristics of modularity and low environmental impact.

Energy storage systems using hydrogen are composed of an electrolyzer (to break the water molecule), a hydrogen storage system and a fuel cell stack (electricity production from hydrogen). As each of these devices has diversified behavior and technology, their efficiencies may be very distinct.

In this paper is described an experimental hydrogen power plant to reproduce practical conditions and evaluation of the real possibilities of such storage systems.

This paper describes the constructive part and automation algorithms of a power plant storage system using hydrogen. Furthermore, an evaluation is performed about the consumption and efficiency of each power component, which are usually scarcely taken into consideration. 
This paper is structured in five sections. Section 1 provides an introduction to the subject discussed in this paper. Section 2 describes the main components of a hydrogen system to generate and store energy composed by an electrolyzer, storage unit and fuel cell stack. Section 3 describes the experimental plant used in the tests, its peripherals and the control system. Section 4 presents the results of experiments performed with each component of the plant, in order to check its operation and performance. In Section 5 is presented a detailed analysis of the plant operation data. Finally, in Section 6, are reunited the final conclusions.

\section{Main components of an energy storage system using hydrogen}

The basic structure of a power plant using hydrogen storage scheme is depicted in Figure 1. This power plant is composed by a rectifier, which converts AC power into DC, an electrolyzer converting DC electrical energy into hydrogen gas, the hydrogen storage, the fuel cell stack to convert hydrogen back into electricity, and the power converter for interconnection with the distribution system.

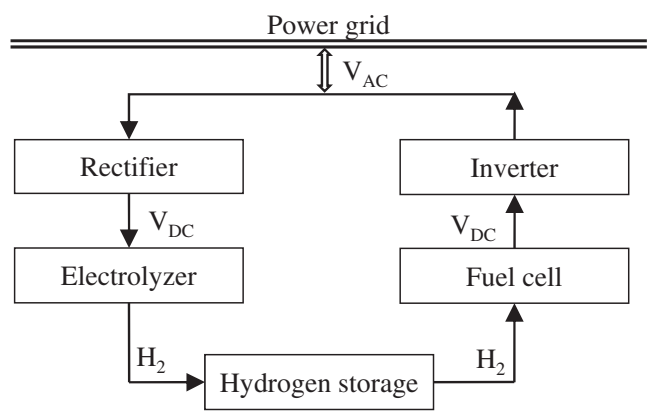

Figure 1: Components of a power plant using hydrogen storage.

\subsection{Electrolyzers}

Electrolyzers are devices used to break the water molecule into its hydrogen and oxygen components. Currently, there are three types of electrolyzers distinguished according to the type of electrolyte used and temperature of operation: alkaline, proton exchange membrane and solid oxide.

- Alkaline Electrolyzers: a mature technology, characterized by two electrodes immersed into a liquid alkaline electrolyte composed by a solution of $20-30 \%$ of potassium hydroxide $(\mathrm{KOH})$. A diaphragm involving the gases produced in the process to ensure high efficiency and safety separates the two electrodes. The diaphragm should also be permeable to hydroxide ions and water [7, 8]. The energy consumption in these cells ranges from 4.2 to $5.9 \mathrm{kWh} / \mathrm{Nm}^{3}$, while in the complete system (stack, converters, pumps and valves) $4.5-7.0 \mathrm{kWh} / \mathrm{Nm}^{3}$. These electrolyzers operate at temperatures between 60 and $80^{\circ} \mathrm{C}$ and less than 30 bar pressure for a few megawatts [9].

- PEM Electrolyzers: are composed by solid proton exchange membranes (PEM). A compact design and operation at high pressures are their main advantages. The energy consumption in the cells is about 4.2-5.6 kWh/ $\mathrm{Nm}^{3}$, while for the complete system is about $4.5-7.5 \mathrm{kWh} / \mathrm{Nm}^{3}$. These electrolyzers operate at temperatures between 50 and $80^{\circ} \mathrm{C}$ and pressures less than 30 bar [9].

- Solid Oxide Electrolyzers (SOEC): in this type of electrolyzer, the hydrogen production is performed at high efficiency, flexible chemistry, high temperatures and pressures, eliminating noble catalysts [9].

\subsection{Hydrogen storage}

Hydrogen can be stored in various forms, such as gas, liquid, or also as an intermediate compound. In this project were considered the following forms:

- Hydrogen storage in gas form: in this natural state, hydrogen has low density (large volumes), leading to difficulties in its storage process. One solution is to store the hydrogen gas by compressing it in high-pressure cylinders. The hydrogen mass becomes $6-10 \%$ volume of the total storage at pressures of 35-70 MPa. Although commercially available, this form of storage is expensive with highenergy consumption, taking about $30 \%$ of the hydrogen energy, troubles with mechanical fracture and insecurity, and the need of an appreciable compressor structure [10].

- Hydrogen storage in liquid form: is the more compact storage means. The hydrogen is stored in cryogenic tanks, typically in isolated cylinders, with a $20 \%$ hydrogen mass at pressures of $0.1 \mathrm{MPa}$ at $-253^{\circ} \mathrm{C}$. The drawbacks of this method are the problems associated with the loss of energy during the $\mathrm{H}_{2}$ liquefaction and evaporation stages [10].

- Hydrogen storage in intermediate compounds: In this method of storage, the hydrogen is adsorbed in solid state of metal hydrides $(\mathrm{MH})$. Under these 
circumstances, the hydrogen takes a potential maximum of about $7 \%$ of mass with $90 \mathrm{~kg} / \mathrm{m}^{3}$, at pressures of 0.1-6.0 MPa. The drawbacks of this type of storage are the distinct adsorption and desorption temperatures. The main advantages are the lower working pressure, representing higher security of operation, and small recharging times, besides occupying lower volumes. The formation/dissociation processes in MH storage tanks require a thermal exchanging system. During formation of the hydrides (exothermic reaction) the tank needs cooling, whereas during dissociation (endothermic reaction) the tank requires heat to recover the stored hydrogen $[10,11]$.

\subsection{Fuel cells}

The electrochemical device called fuel cell (FC) consists of an electrolyte (membrane) conductor of ions, an anode, and a porous cathode, which convert energy from chemical reactions directly into electricity. For FC PEM (Proton Exchange Membrane), the electrochemical combination of the fuel (hydrogen) with the oxidizer (oxygen) produces continuous electricity, heat and water $[12,13]$.

This type of FC operates at temperatures around 20$80^{\circ} \mathrm{C}$, with an efficiency of around $40-60 \%$, and operates without any damage to the membrane if kept well hydrated. The relative humidity of the membrane has to be kept in a range between 85 and $100 \%$, but without condensation [10].

Due to their characteristics of operation, the PEM FCs are been highly considered candidates for distributed energy generation, due to its relatively low operating temperature, quick start and its production of water as waste and high power density [10].

\section{Prototype of an energy storage system using hydrogen}

The energy storage system discussed in this paper was designed so that the fuel cell could operate at full load for three hours, typical to attend periods of high power demand peaks. Figure 2 presents the layout of the hydrogen storage power plant and Figure 3 shows its physical structure.

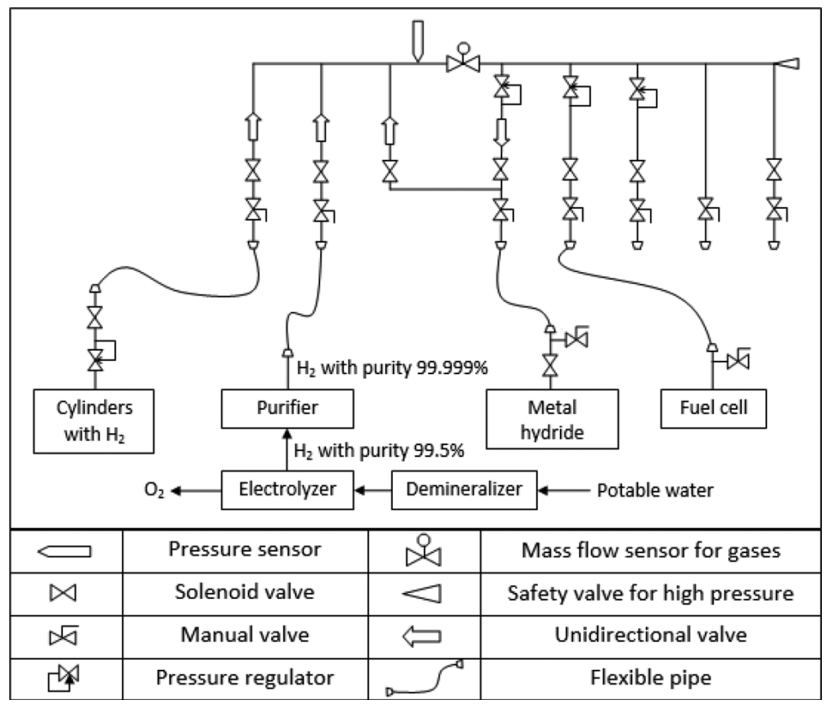

Figure 2: Connection layout of the plant components.
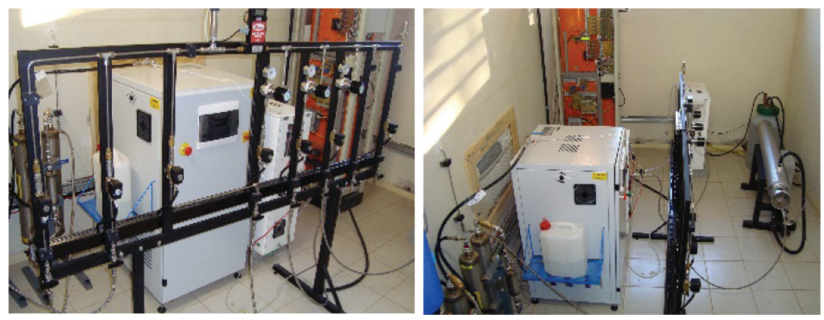

Figure 3: Power plant using hydrogen.

\subsection{Hydrogen bus}

The experimental power plant proposed in this paper is made of three hydrogen sources (pressurized tanks, electrolyzer and metal hydrides) and two consumer loads (metal hydrides and FC). A hydrogen circuit with sensors and valves performs measurement and control of the whole process, as illustrated in Figures 2 and 3. Thus, by monitoring some vital points and using a control program, it is possible to establish different conduction gas pathways in the hydrogen circuit.

From pressurized tanks, the hydrogen is injected into FCs or stored in metal hydrides in accordance to an opening and closure combination of valves. The purified hydrogen generated by the electrolyzer is stored in metal hydrides or injected directly into the FC. In a similar way, the hydrogen stored in metal hydrides is used to supply the fuel cell.

In Figure 2, the hydrogen mass sensor is strategically located to measure the hydrogen flow from any of the 
three sources or consumers. Another sensor measures the pressure in the equipment.

In addition, manual pressure control valves, to increase the plant safety levels, were installed next the equipment and to serve as decontaminant drains to remove any possible unwanted residues when a pipe is disconnected.

\subsection{Alkaline electrolyzer}

The choice of the alkaline electrolyzer for this project is due to its technological maturity level and easy commercial availability.

The hydrogen production is made by a commercial alkaline electrolyzer, HP model manufactured by PielMcPhy Energy. Technical specifications of this electrolyzer are listed in Table 1 [14].

Table 1: Technical Specifications of Electrolyzer - Model HP.

\begin{tabular}{ll}
\hline Work pressure & $\leq 15 \mathrm{bar}$ \\
Hydrogen production & $\leq 6.67 \mathrm{NL} / \mathrm{min}$ \\
Oxygen production & $\leq 3.33 \mathrm{NL} / \mathrm{min}$ \\
Hydrogen purity & $99.5 \pm 0.2 \%$ \\
Electrical voltage & $220 \mathrm{~V} / 60 \mathrm{~Hz}$ \\
Electrical energy & $\leq 3 \mathrm{kWh}$ \\
Water consumption & $\leq 0.00667 \mathrm{~L} / \mathrm{min}$
\end{tabular}

Source: Mcphy/Piel.

The electrolyzer data assure a hydrogen purity of $99.5 \%$. However, according to the FC manufacturer's specifications, the minimum purity of the input hydrogen must be at least $99.995 \%$. Then to elevate the purity degree and ensure the FC proper functioning, one purifier was installed at the output of the electrolyzer increasing hydrogen purity to $99.999 \%$.

In addition to the above precautions, the water in the electrolyzer had to be free from minerals that could impair its safe operation. Thus, it was installed an inlet demineralizer.

\subsection{Metal hydride}

Hydrogen storage in metal hydrides $(\mathrm{MH})$ is used in this project because it works at low pressures and do not demand for pressurizers (reductions of cost, maintenance and losses). So, the plant safety is higher since generation, consumption (FC) and hydrogen storage work at low pressures ( $<15$ bar).
The $\mathrm{MH}$ cylinder used in this project is the HBOND7000L model manufactured by LabTech, whose technical specifications are listed in Table 2. The layout is presented in Figure 4 [15].

Table 2: Technical Specifications of MH Cylinder - Hbond-7000L.

\begin{tabular}{ll}
\hline Chemical composition & $(\mathrm{LaCe}) \mathrm{Ni5}$ \\
Loading pressure & $\leq 15 \mathrm{bar}$ \\
Temperature load & $20-25^{\circ} \mathrm{C}$ \\
Discharge pressure & $2-10 \mathrm{bar}$ \\
Discharge temperature & $10-30^{\circ} \mathrm{C}$ \\
Hydrogen purity & $\geq 99.9 \%$ \\
Storage capacity of hydrogen & $7,140 \mathrm{~L}(0.64 \mathrm{~kg})$ \\
Alloy mass & $46 \mathrm{~kg}$ \\
\hline
\end{tabular}

Source: LabTech.

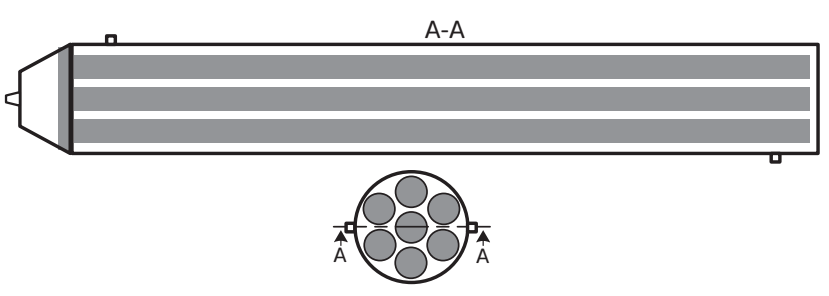

Figure 4: Layout of metal hydrides tanks in the cylinder.

The typical hydrogen storage reaction as an intermediate compound in the adsorption and desorption in a metal alloy is shown in (1) [16].

The direct interaction is an exothermic process (heat release Q) in which the hydrogen is adsorbed by the alloy forming the metal hydride compound. In the reverse reaction, the hydrogen is released from the alloy by supplying certain amount of heat energy (exothermic reaction) [16].

$$
\mathrm{M}(\mathrm{s})+\mathrm{x} / 2 \mathrm{H}_{2} \underset{\text { desorption }}{\stackrel{\text { adsorption }}{\rightleftarrows}} \mathrm{MH}_{\mathrm{x}}(\mathrm{s})+\mathrm{Q}
$$

where $\mathrm{M}$ is a metal alloy (LaNi5, TiFe, etc.), and (s) and (g) refer to the solid and gas states, respectively.

The heat released in the adsorption process must be removed, since the adsorption rate decreases with an increasing temperature [17]. For that, water circulates (at ambient temperature, approximately $25^{\circ} \mathrm{C}$ in the internal pipes of the cylinder (Figure 4). On the other hand, desorption of hydrogen is an endothermic reaction, which removes heat from the environment. Therefore, the metal hydrides must be heated so that the stored hydrogen is released by circulating heated water through the internal pipes of the cylinder [18-20]. 
Selection of the water source (hot or cold) in the $\mathrm{MH}$ thermal exchanges was made through activation of solenoid valves to configure adequately the circuit as shown in Figure 5. The pump is of a membrane type and has a speed control performed by a monitor and control program also used to control the solenoid valves (V1, V2, V3 and V4), monitors the water flow (F1), the water temperatures in hot (T1) and cold (T2) reservoirs, and water temperature of the cylinder output (T3).

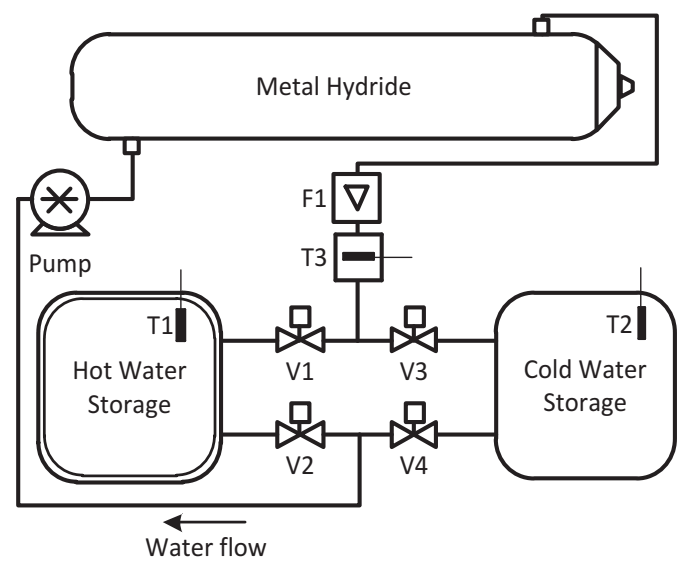

Figure 5: Layout of the MH cylinder temperature control.

\subsection{PEM fuel cell}

Selection of this type of FC was due to its technological maturity level, commercial availability, low operating temperature, quick startup time, and cause only of a low environmental impact.

The energy storage plant discussed in this paper has a fuel cell module depicted in Figures 2 and 3. The FC module model is the GreenHub 3000 model manufactured by Horizon Fuel Cells Technologies. Each module is equipped with the FC basic controls, such as temperature, pressure of the inlet reagents, periodic short circuiting system for voltage recovery, and protection devices. The whole module contains also a DC/DC converter and a $\mathrm{DC} / \mathrm{AC}$ single-phase inverter across its output providing $220 \mathrm{~V} / 60 \mathrm{~Hz}$. The main technical specifications of each FC module are listed in Table 3 [21].

\subsection{Monitor and control program}

To monitor and control the storage plant was used a supervisory program developed in a LabVIEW platform to provide high interactivity with operational quantities.
Table 3: Technical Specifications of FC and GreenHub-3000 Module.

\begin{tabular}{ll}
\hline FC model & $\mathrm{H}-3000$ \\
Cells number & 72 \\
Peak power & $3,000 \mathrm{~W}$ \\
Stack voltage & $\leq 65 \mathrm{~V}$ \\
Nominal power output & $2,550 \mathrm{~W}$ \\
Hydrogen pressure in the cell inlet & $0.45-0.55 \mathrm{bar}$ \\
Hydrogen pressure in the module inlet & $7-10 \mathrm{bar}$ \\
FC performance & $43.2 \mathrm{~V} @ 70 \mathrm{~A}$ \\
Maximum temperature operation & $65^{\circ} \mathrm{C}$ \\
Hydrogen purity & $\geq 99.995 \%$ \\
Consumption of hydrogen & $\leq 42 \mathrm{~L} / \mathrm{min}$ \\
Stack efficiency & $40 \% @ 43.2 \mathrm{~V}$ \\
\hline
\end{tabular}

Source: Horizon Fuel Cells Technologies.

A dedicated computer and data acquisition system were used to track the main variables.

Data flow between the supervisory program and the plant is shown in Figure 6 with the controlled variables.

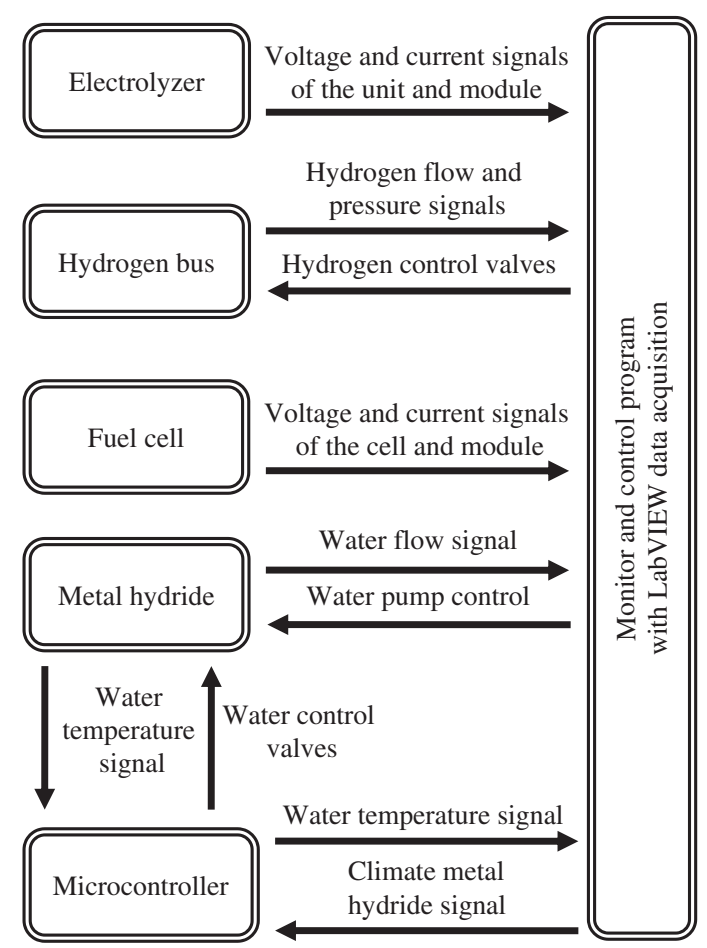

Figure 6: Data flow between the plant and the supervisory program.

\section{Experimental results}

A wide range of different interrelated physical quantities were registered by the data acquisition system and supervisory program, and stored in a disk to be restored and processed offline. 


\subsection{Electrolyzer}

The electrical signals captured along the electrolyzer experimental tests were stack output voltage and current (electrolyzer unit itself) and the whole module (stack, power supply, power converter, ventilation system, valves, and circuits of monitoring, actuation and control, etc.).

The stack internal pressure was set at 10 bar to allow measurement of the net consumed and converted energies into hydrogen storage, because the hydrogen volume drained at electrolyzer output is equal to its maximum capacity.

Figure 7 illustrates the electrolyzer operation and the measured powers. The $\mathrm{H}_{2}$ flow and energy density (3.29 $\mathrm{kWh} / \mathrm{L}$ ) were used to calculate the amount of converted power in $\mathrm{H}_{2}$ [12].

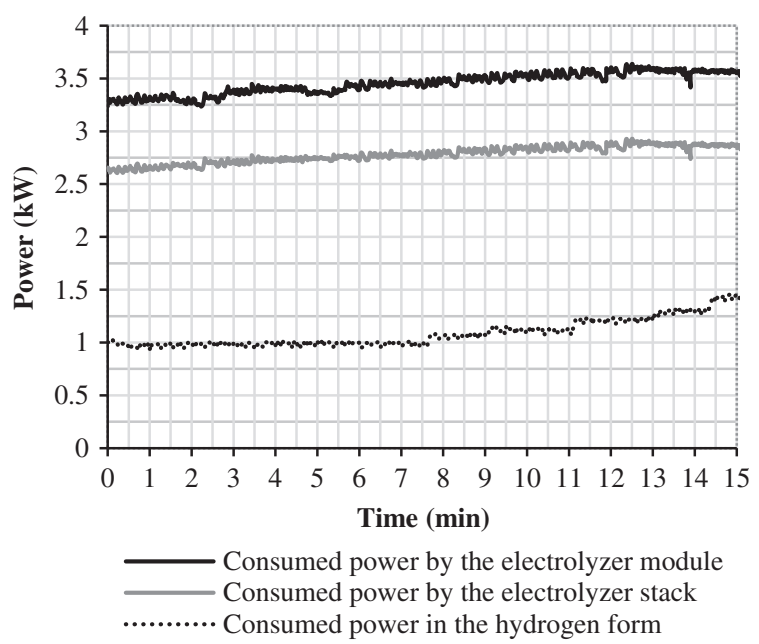

Figure 7: Powers in electrolyzer operation.

During the electrolyzer operation, the power consumption has increased as well as the hydrogen production and, consequently, the electrolyzer efficiency, as shown in Figure 8. This efficiency increases from 30 to $40 \%$ due to elevation of the internal electrolyzer temperature. During these experimental tests, the electrolyzer temperature changed from 30 to near $50^{\circ} \mathrm{C}$.

To verify the temperature dependence, an experiment was carried out with the electrolyzer with an internal operating temperature of $49^{\circ} \mathrm{C}$. The average hydrogen production, obtained from the flow sensor signals and the electrolyzer efficiency are shown, respectively, in Figures 9 and 10.

In Figure 10 can be seen that the average electrolyzer efficiency is around $33 \%$ for a $49^{\circ} \mathrm{C}$ operating temperature.

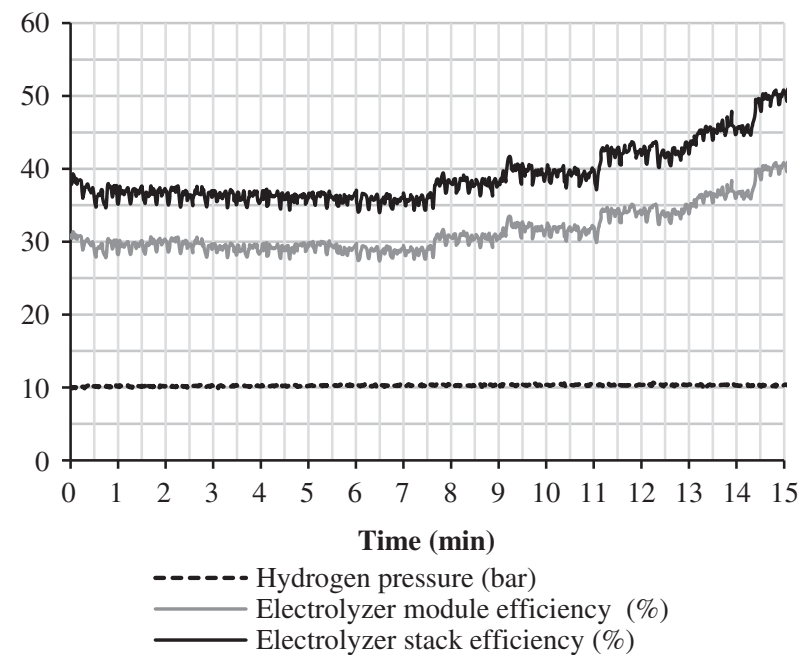

Figure 8: Efficiencies and hydrogen pressure in electrolyzer operation.

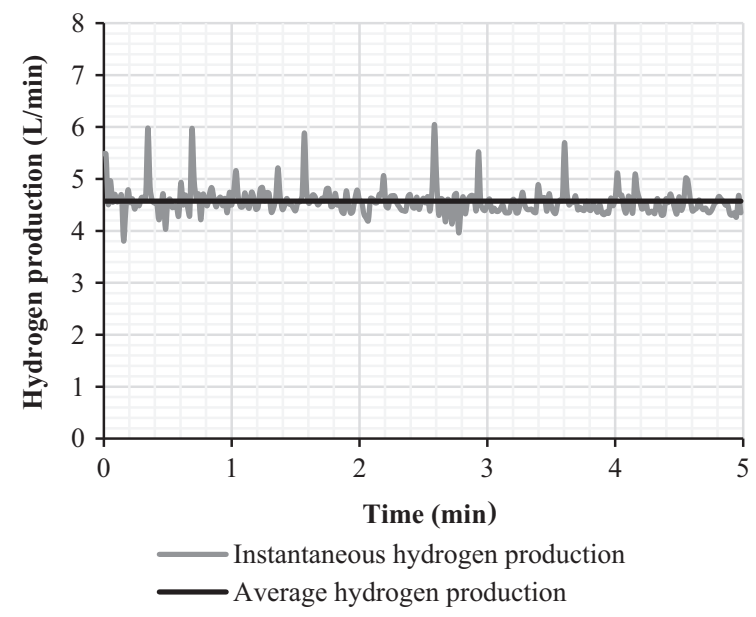

Figure 9: Hydrogen production by electrolyzer at a constant temperature.

\subsection{Fuel cell}

The hydrogen used in the FC experimental tests came from the $\mathrm{MH}$, which was previously generated by the electrolyzer.

To verify the fuel cell operation, a load was connected across the module output and was increased gradually. The powers involved during the tests are presented in Figure 11.

The difference between the FC stack output power and the load-consumed power is due to module internal losses (power converter, ventilation system, valves, and circuits of monitoring, actuation and control, etc.).

It is observable in Figure 11, that the hydrogen consumed power has numerous peaks. These surges are 


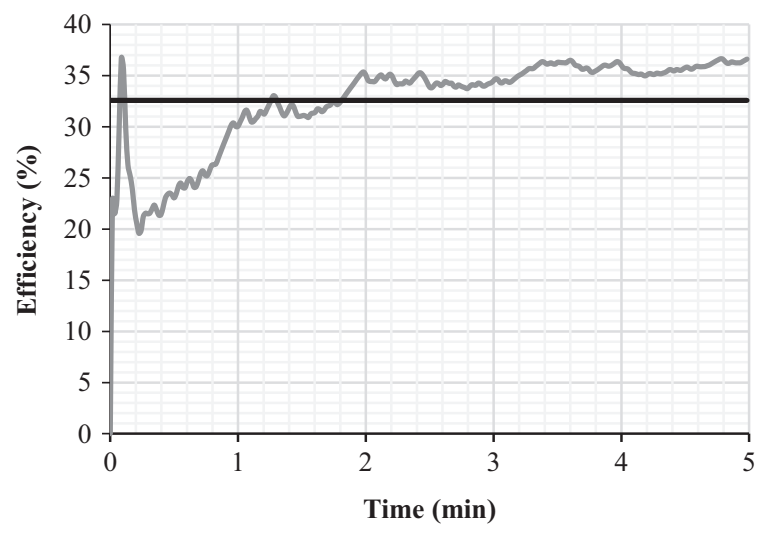

Stack efficiency — Average stack efficiency

Figure 10: Electrolyzer efficiency at a constant temperature.

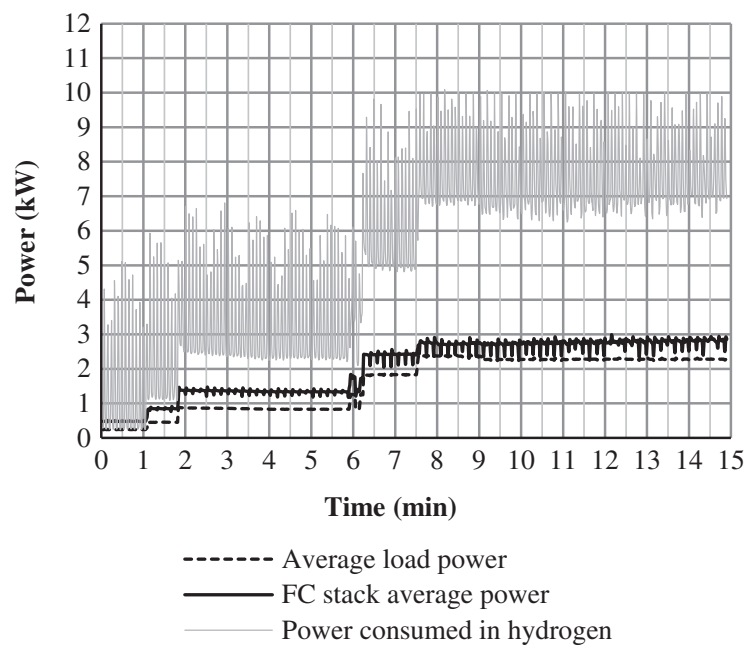

Figure 11: Powers in fuel cell operation.

caused by the FC module internal control of pressurized $\mathrm{H}_{2}$ to expunge water, which is result of the chemical reactions, to the outside [22-24]. This expunge technique introduces hydrogen losses, and consequently, power losses.

Figure 12 presents the FC stack output voltage with the respective hydrogen consumption at 1 min lasting experiment. In this figure, the periodicity of hydrogen consumption peaks is about $5 \mathrm{~s}$. However, as the rate of hydrogen release is independent of load, this method introduces a module fixed loss.

Similarly, short circuits across the commercial FC stack terminals are applied at fix periods every $10 \mathrm{~s}$. After each short circuit there is a slight recovery of the original cell voltage, justifying so the use of this technique to humidify the cell membranes and to reduce the ohmic losses [25]. Similarly, the purge techniques of

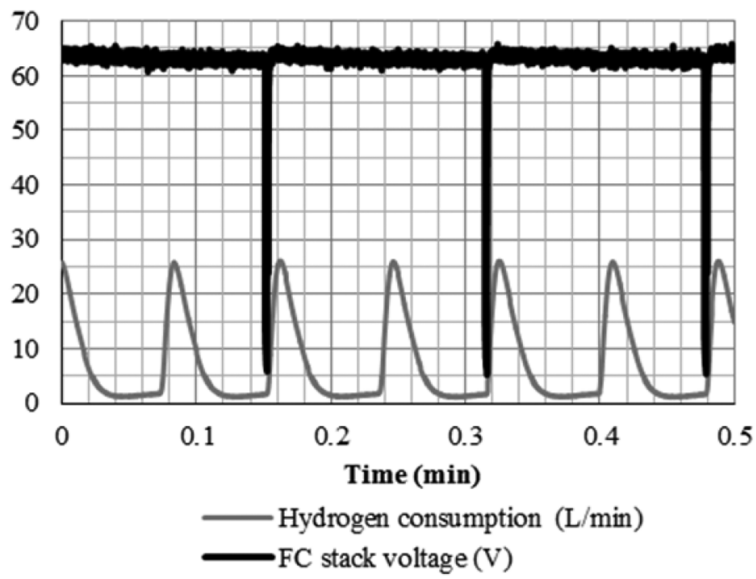

Figure 12: FC stack output voltage and hydrogen consumption.

hydrogen and water are also performed periodically, without taking into account the voltage drop level by ohmic losses.

Figure 13 displays the FC stack and module efficiency variations along the experiment.

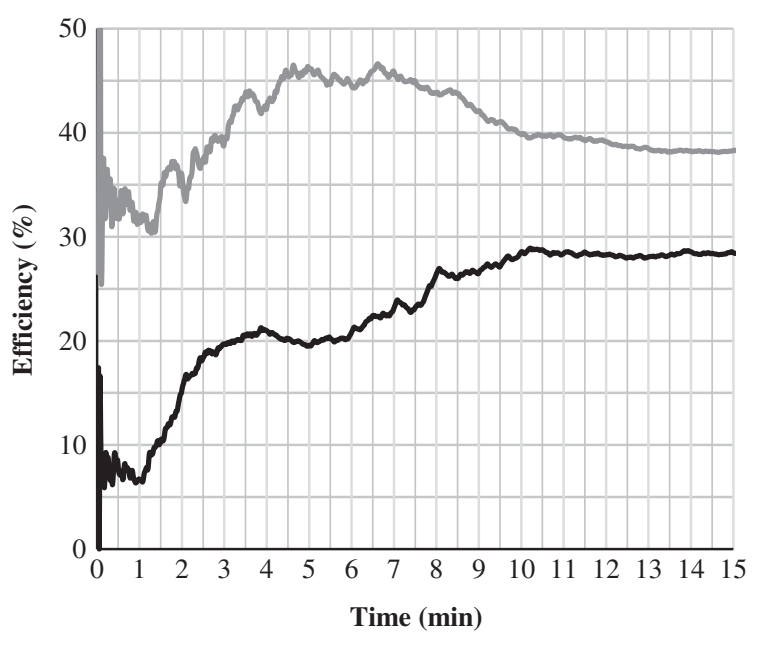

— FC module efficiency —

Figure 13: Efficiencies in fuel cell operation.

In Figure 13 is noticeable that the FC stack efficiency rises with an increases load approximately up to 6 min due to fixed low losses compared to the load power magnitude. At about $7.5 \mathrm{~min}$ there is a load increase, causing a higher voltage drop across the stack terminals dropping its efficiency to $38 \%$. The FC module efficiency at full load remains at approximately $28 \%$. Note that the efficiency amounts were obtained from the relationship between the energy contained in the volume of hydrogen entering the FC module and the output power in stack 
and module. Thus, the efficiency calculations include the energy losses associated with hydrogen used to expunge water out of the membrane.

\subsection{Metal hydrides}

For operation of the storage plant, the metal hydride cylinder was previously charged with the hydrogen produced in the electrolyzer. During the experimental tests, $\mathrm{MH}$ supplied hydrogen to the fuel cell. Variations in the main quantities involved in the metal hydride operation are shown in Figure 14.

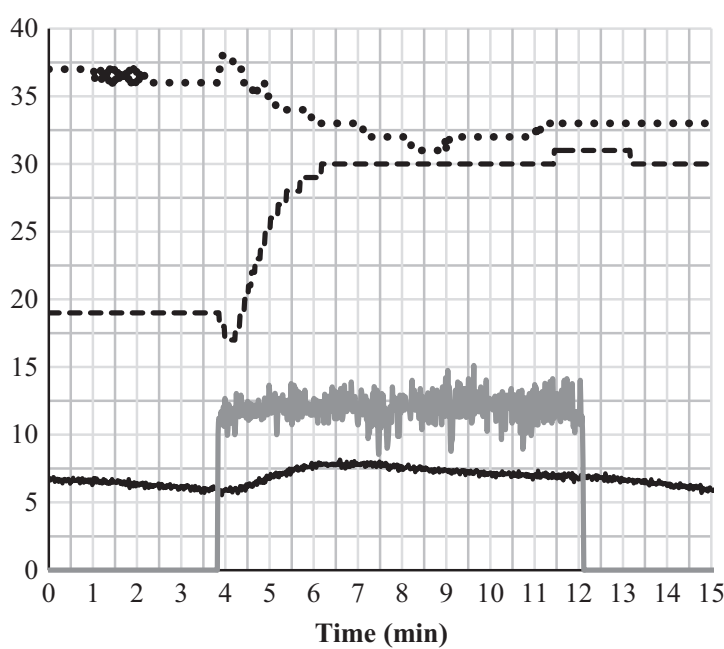

Hydrogen pressure (bar)

..... Water temperature at the $\mathrm{MH}$ inlet $\left({ }^{\circ} \mathrm{C}\right)$

- - - W Water temperature at the $\mathrm{MH}$ outlet $\left({ }^{\circ} \mathrm{C}\right)$

Water flow (L/min)

Figure 14: Physical quantities in metal hydrides operation.

It is observable in Figure 14 that initially the hydrogen pressure decreases along the desorption process. However, after $4 \mathrm{~min}$, the activation of the water circulation pump through the inner metal hydrides pipes reestablished the pressure line. On the other hand, after stopping the water pump, after $12 \mathrm{~min}$, the line pressure dropped down again. The pressure reestablishment through forced water circulation is due to an increase of the hydride temperature since desorption is a temperature dependent process. The MH thermal exchanges were monitored by the water temperature rise at the cylinder output after starting the water pump.

The cold and hot waters used in the metal hydride heat exchanges are provided by renewable sources. The cold water comes from geothermal exchangers and the hot water, from solar heaters. Thus, the thermal energy exchanged with the metal hydride was neglected since no electricity was used in the hydrogen adsorption and desorption processes [26].

\section{Analysis of the results}

In the experiments described above, the electrolyzer module operated at efficiencies from 30 to $40 \%$ whereas the electrolyzer unit worked at efficiencies from 36 to $50 \%$, therefore confirming its direct dependence on the internal operating temperatures. The load connected across the FC module had an important influence on its overall efficiency (from 7 to $28 \%$ ) and on the stack efficiency (from 31 a 46\%) due to the internal and constant losses imposed by the expunge water system. The $\mathrm{MH}$ cylinder proved to be a safe, compact and viable alternative for hydrogen storage, without need of any compressors. The whole power plant had efficiencies that oscillated between 2.1 and $11.2 \%$, mainly due to losses in the control modules of the electrolyzer and FC. The total efficiency of the plant can be increased by using larger power converters and modern electrolyzers such as those PEM based ones. Another way to increase the efficiency of the fuel cell module is to implement techniques to optimize the periodic short circuits and hydrogen purge systems.

In a hypothetical situation, considering only the efficiencies of the electrolyzer unit and the FC stack, i.e., without losses related to the module internal components (power supplies, power converters, ventilation systems, valves, and the electronic circuits), the power plant would present an overall efficiency between 11.16 and $23 \%$. In fact, the overall efficiency could be higher, since the calculation of FC efficiency includes the associated losses to the hydrogen expunge technique.

New studies must be performed in this unit storage and power generation system (electrolyzer, HM and FC) to optimize the operation of each device by refining and improving the overall efficiency.

\section{Conclusion}

This paper describes an experimental power plant integrating a metal hydride hydrogen storage, an alkaline electrolyzer and PEM fuel cells for storage and generation of electrical and heat energy. 
The experimental storage plant described in this paper made possible data collection for each individual component operation and the whole system of a hydrogen storage scheme using metal hydrides. The data so far obtained plays a key role in assessing some important features of performance and efficiency of each individual device. These data will contribute for future researches of the control laws to maximize the overall system efficiency and henceforth to widen the scope of hydrogen storage and power generation industry.

\section{References}

1. Tan H, Wang B, Liu D, Guo S. Analysis of distributed generation system based on micro-grid and its impaction on voltage distribution. In Power and Energy Engineering Conference. APPEEC, 2011.

2. Miller T, Edmonds M. Energy storage can enable wider deployment of distributed generation. In 22nd International Conference and Exhibition on Electricity Distribution CIRED 2013, Stockholm, 2013.

3. Salman SK. The impact of embedded generation on voltage regulation and losses of distribution networks. IEE Colloquium on the Impact of Embedded Generation on Distribution Networks,London, 1996.

4. Xiaojuan H, Xiwang C, Xilin Z, Tao Y, Zhanzhan Q, Chengmin W. Distributed generation system design dased on energy storage converter technology. In 10th World Congress on Intelligent Control and Automation WCICA, 2012.

5. Carnegie R, Gotham D, Nderitu D, Preckel PV. Utility scale energy storage systems: benefits, applications and technologies, Purdue University: State Utility Forecasting Group, 2013.

6 Shuang Y, Mays TJ, Dunn RW. A new methodology for designing hydrogen energy storage in wind power systems to balance generation and demand. In International Conference on Sustainable Power Generation and Supply SUPERGEN'09, 2009.

7. Ulleberg 0. Modeling of advanced alkaline electrolyzers: a system simulation approach. Int J Hydrogen Energy 2003; 28:21-33.

8. Carnieletto R, Parizzi JB, Farret FA. An overall efficiency and thermal behavior model for high power electrolyzers. In VIII International Conference on Industry Applications (INDUSCON), Poços de Caldas - MG, 2008.

9. Carmo M, Fritz DL, Mergel J, Stolten D. A comprehensive review on PEM water electrolysis. Int J Hydrogen Energy 2013;38:4901-34.
10. Linardi M. Introdução à Ciência e Tecnologia de Células a Combustível. São Paulo, Brazil: Artliber, 2010.

11. Dhaou SH, Askri F, Mellouli S, Jemni A, Nasrallah S. Experimental study and characterization of metal hydride containers. Int J Hydrogen Energy 2011;36:4952-7.

12. Larminie J, Dicks A. Fuel cell systems explained. England: John Wiley \& Sons, 2003.

13. United States Department of Energy. Fuel cell handbook. 7th ed. Morgantown: EG \& G Technical Services, 2004

14. McPhy Energy. Available at: http://www.mcphy.com. Accessed: 27 May 2013.

15. LabTech. HBond - 7000L. Available at: http://www.labtechhydrogen.com/index.php?page=HS3. Accessed: 21 December 2015.

16. Lototskyy MV, Yartys VA, Pollet BG, Bowman RC. Jr. Metal hydride hydrogen compressors: a review. Int J Hydrogen Energy 2014;39:5818-51.

17. Laurencelle F, Dehouche Z, Goyette J, Bose TK. Integrated electrolyser-metal hydride compression system. Int J Hydrogen Energy 2006;31:762-8.

18. Muthukumar P, Groll M. Metal hydride based heating and cooling systems: a review. Int J Hydrogen Energy 2010;35:3817-31.

19. Krokos CA, Nikolic D, Kikkinides ES, Georgiadis MC, Stubos AK. Modeling and optimization of multi-tubular metal hydride beds for efficient hydrogen storage. Int J Hydrogen Energy 2009;34:9128-40.

20. Raju M, Kumar S. Optimization of heat exchanger designs in metal hydride based hydrogen storage systems. Int J Hydrogen Energy 2012;37:2767-78.

21. Horizon Fuel Cell. Available at: http://www.horizonfuelcell.com. Accessed: 27 May 2013.

22. Hou Y, Shen C, Yang Z, He Y. A dynamic voltage model of a fuel cell stack considering the effects of hydrogen purge operation. Renewable Energy 2012;44:246-51.

23. Nikiforow K, Karimäki H, Keränen TM, Ihonen J. Optimization study of purge cycle in proton exchange membrane fuel cell system. J Power Sources 2013;238:336-44.

24. Mokmeli A, Asghari S. An investigation into the effect of anode purging on the fuel cell performance. Int J Hydrogen Energy 2010;35:9276-82.

25. Kim J, Kim D, Kim S, Nam SW, Kim T. Humidification of polymer electrolyte membrane fuel cell using short circuit control for unmanned aerial vehicle applications. Int J Hydrogen Energy 2014;39:7925-30.

26. Gonzatti F, Ferrigolo FZ, Kuhn VN, Franchi D, Farret FA. Automation of thermal exchanges of cylinders metal hydride integrated with energy storage. In: The 7th International Conference Industry (INDUSCON), Juiz de Fora, MG, Brazil, 2014. 